\title{
INFLUÊNCIA DA DIETA COM DIFERENTES NÍVEIS DE LIPÍDEO E PROTEÍNA NA RESPOSTA FISIOLÓGICA E HEMATOLÓGICA DE REPRODUTORES CAPRINOS SOB ESTRESSE TÉRMICO ${ }^{1}$
}

\author{
Influence of diet with different levels of lipid and protein in the physiologic \\ and hematological responses of buck goat under thermal stress
}

\author{
Gustavo de Assis Silva ${ }^{2}$, Bonifácio Benício de Souza ${ }^{3}$, Carlos Enrique Peña Alfaro ${ }^{4}$, \\ Jeferson Azevedo Neto ${ }^{5}$, Solange Absalão Azevedo ${ }^{6}$, Elisângela Maria Nunes da Silva ${ }^{7}$, \\ Rosangela Maria Nunes da Silva ${ }^{6}$
}

\begin{abstract}
RESUMO
Este trabalho foi desenvolvido no Centro de Saúde e Tecnologia Rural da Universidade Federal de Campina Grande - Campus de Patos-PB. Com o objetivo de verificar se dietas com diferentes níveis de lipídeo e proteína no período mais quente do ano (Novembro a Dezembro) influenciam na resposta fisiológica e hematológica de reprodutores caprinos sob estresse térmico. Foram utilizados 27 reprodutores caprinos, mestiços de Anglo-Nubiano com caprinos sem raça definida (SRD). Distribuídos num delineamento inteiramente casualizado no esquema fatorial $3 \times 3 \times 2$, três níveis de lipídeos (2, 4 e $6 \%$ ), três níveis de proteína (12, 15 e 18\%) e dois turnos (manhã e tarde) com três repetições. Alimentados com dietas balanceadas compostas por: farelos de milho, trigo e soja, feno de Tifton (Cynodon spp.), mistura mineral e como fonte de lipídeo óleo de girassol. As leituras dos dados meteorológicos foram realizadas duas vezes por dia às 9:00 horas da manhã e às 15:00 horas da tarde. Os parâmetros fisiológicos: temperatura retal (TR), freqüência respiratória (FR) e temperatura superficial (TS) foram aferidos dois dias por semana nos dois turnos às 9:00 horas da manhã e às 15:00 horas da tarde. Foi coletada uma amostra de sangue, para a realização de eritrograma. As médias das temperaturas foram de $37,21^{\circ} \mathrm{C}$ para a máxima e $25,25^{\circ} \mathrm{C}$ para a mínima. Os valores do índice temperatura do globo negro e umidade (ITGU) para os turnos da manhã e tarde foram de 80,16 e 87,17, respectivamente. Não se verificou efeito $(\mathrm{P}>0,05)$ das dietas sobre os parâmetros TR e FR. Com relação ao fator turno houve efeito significativo $(\mathrm{P}<0,05)$ para TR e FR. Para a TS houve interação significativa $(\mathrm{P}<0,05)$, para a dieta com $15 \%$ de proteína e $2 \%$ de lipídeo e para o turno. A análise de variância não revelou efeito significativo $(\mathrm{P}>0,05)$ das dietas sobre os parâmetros sanguíneos, hematócrito (HT), eritrócitos (ER), hemoglobina (HB), hemoglobina corpuscular média (CHCM) e volume globular médio (VGM). Os diferentes níveis de proteína e lipídeo na dieta não exerceram efeito sobre os parâmetros fisiológicos e hematológicos dos animais estudados nas condições desse experimento.
\end{abstract}

Termos para indexação: Estresse calórico, energia, parâmetros fisiológicos, eritrograma.

\begin{abstract}
This work was developed in the Center of Health and Rural Technology at Federal University of Campina Grande - Campus of Patos-PB. The objective was to test the diets with different lipid and protein levels in the highest temperature of the year (November to December) on the physiological and hematological parameters of the buck goats kept under thermal stress. A total of 27 buck goats crossbred of the Anglo-Nubiano with buck goat without defined bred were used. The buck were allocated into a completely randomized design in a $3 \times 3 \times 2$ factorial scheme, three lipids levels (2, 4 and 6\%), three protein levels (12, 15 and 18\%) and two periods (morning and afternoon) with three repetitions. The buck goats were fed with balanced diets based on: corn crumbs, wheat and soybean meal , hay of Tifton (Cynodon spp.), it mixes mineral and and sunflower oil as a lipid source. The meteorological data were done twice a day at the 9:00 am and 15:00 pm. The physiological parameters rectal temperature (TR), respiratory frequency (FR) and surface temperature (TS) were checked two days a week in the two periods at 9:00am and 15:00 pm. A sample of blood was collected, for the erythrogram analysis. The temperatures ranged from $37,21^{\circ} \mathrm{C}$ to $25,25^{\circ} \mathrm{C}$. The values of the black globe and humidity index temperature (BGHI) for the shifts of the morning and afternoon were of 80,16 and 87,17 , respectively. There was no effect $(\mathrm{P}>0,05)$ of the diets on the parameters TR and FR. In relation to the periods also shown no significant effect $(\mathrm{P}<0,05)$ on the TR and FR. The data shown a significant interaction $(\mathrm{P}<0,05)$, for the diet with $15 \%$ of protein and $2 \%$ of lipid on the periods studied.. The variance analysis did not show any significantive effect $(\mathrm{P}>0,05)$ of the diets on the blood parameters, hematócrit $(\mathrm{HT})$, erythrocyte (ER), hemoglobin (HB), hemoglobin medium corpuscular (CHCM) and medium globular volume (VGM). The different protein levels and lipid in the diet did not show any effect on the physiologic and hematological parameters on the buck goats reared under thermal stress tested.
\end{abstract}

Index terms: Heat stress, energy, physiology responses, erythrogran

(Recebido para publicação em 3 de dezembro de 2004 e aprovado em 14 de novembro de 2005)

\footnotetext{
1 Pesquisa Financiada CAPES/CNPQ/UFCG/PATOS-PB.

${ }^{2}$ Mestrando em Medicina Veterinária de Pequenos Ruminantes CSTR/UFCG/Patos, PB. gugavet2000@yahoo.com.br

${ }^{3}$ Orientador e Professor Adjunto do Departamento de Medicina Veterinária CSTR/UFCG - 58.700-000 - Patos, PB

${ }^{4}$ Professor Adjunto Departamento de Clínicas Veterinárias CSTR/UFCG/Patos, PB.

${ }^{5}$ Doutorando do Curso de Medicina Veterinária UFRPE.

${ }^{6}$ Professor do Departamento de Medicina Veterinária CSTR/UFCG/Patos, PB

${ }^{7}$ Professora Substituta do Departamento de Clínicas Veterinárias CSTR/UFCG/Patos, PB.
} 


\section{INTRODUÇÃO}

O consumo de ração pelos animais é controlado por três principais mecanismos fisiológicos: volume de ingesta no trato digestivo, densidade energética de nutrientes no sangue e estresse calórico (BRIDGES et al., 1992). Recentemente alguns trabalhos têm demonstrado uma maior preocupação com relação ao bem estar animal, já que existe um conhecimento relativo entre o estresse calórico e a produtividade, em sistemas intensivos e extensivos de criação (SILANIKOVE, 2000).

Quando os caprinos estão em uma zona de termoneutralidade o mínimo de energia é requerida para manter constante a temperatura corporal. Entretanto, quando esses animais são expostos a temperaturas ambientais acima ou abaixo da temperatura crítica, superior e inferior, há uma necessidade de energia adicional para manter o comportamento fisiológico. Portanto, em situação estressante, a energia se torna um fator limitante, devido ao seu maior requerimento e menor fornecimento, em virtude da redução da ingestão de alimentos (LU, 1989). Dessa forma, o incremento calórico da atividade voluntária da fermentação ruminal, digestão do alimento, absorção de nutrientes e metabolismo ficam reduzidos devido a pouca ingestão de alimento, o que resulta numa pequena quantidade de calor dissipado beneficiando o balanço energético entre os animais e o ambiente (APPLEMAN \& DELOUCHE, 1958).

Entretanto, com a redução na ingestão de matéria seca, desencadeada pelo estresse calórico, ocorre um balanço energético negativo, que resulta em falta de nutrientes, para o crescimento, produção e reprodução. Além da redução na ingestão de alimentos, o estresse térmico também provoca alterações fisiológicas (MULLER et al., 1994) e hematológicas (PAES et al., 2000) parâmetros que têm sido utilizados mundialmente para avaliar o estado de saúde dos animais e também, como indicadores de resistência ao estresse térmico.

Portanto, a busca de dietas que viessem a suprir as necessidades dos animais, sem aumentar o calor produzido pela fermentação ruminal, despertou o interesse em alguns pesquisadores pelo uso de lipídeos na alimentação de ruminantes, pois além de aumentar a densidade energética da dieta sem riscos de distúrbios nutricionais, decorrentes do aumento da proporção de concentrados (SALLA et al., 2003) a adição de lipídeos, aumenta a eficiência energética da dieta pela redução da metanogênese (GIGER-REVERDIN et al., 2003) e do incremento calórico, permitindo um maior consumo de energia.
Dessa forma, a suplementação com gordura pode reduzir o incremento calórico da dieta, melhorar a utilização do nitrogênio, e conseqüentemente, o bem-estar animal (BUNTING et al., 1992; WEST, 1999). Entretanto, informações pertinentes ao manejo nutricional de caprinos para melhorar a eficiência produtiva, sob estresse térmico são quase inexistentes.

Com o presente trabalho objetivou-se verificar o efeito de dietas com diferentes níveis de lipídeos e proteína nos meses mais quentes do ano (Novembro e Dezembro) sobre a resposta fisiológica e hematológica de reprodutores caprinos sob estresse térmico.

\section{MATERIAL E MÉTODOS}

O trabalho foi desenvolvido no Centro de Saúde e Tecnologia Rural (CSTR) da Universidade Federal de Campina Grande (UFCG), localizado na cidade de Patos$\mathrm{PB}$, região Semi-Árida da Paraíba, no período de novembro e dezembro de 2003. Foram utilizados 27 reprodutores caprinos machos mestiços de Anglo-Nubiano com SRD, alimentados com dietas balanceadas de acordo com recomendações do AGRICULTURAL AND FOOD RESEARCH COUNCIL (AFRC, 1995) oferecidas em duas porções iguais e correspondentes a 3\% do peso corporal, compostas por: farelos de milho, trigo e soja, feno de Tifton (Cynodon spp.), calcáreo, fosfato bicálcico, mistura mineral e como fonte de lipídeo, óleo de girassol de acordo com a Tabela 1.

Os animais foram distribuídos num delineamento inteiramente casualizado no esquema fatorial $(3 \times 3 \times 2)$, três níveis de lipídeo (L) (2, 4 e 6\%), três níveis de proteína (PB) $(12,15$ e 18\%) e dois turnos (manhã e tarde) com três repetições e para os parâmetros hematológicos foi utilizado o delineamento inteiramente casualizado no esquema fatorial ( 3 x 3), três níveis de lipídeo e três níveis de proteína, com três repetições.

Para registrar os dados meteorológicos foram instalados no local do experimento um termômetro de máxima e mínima, um termômetro de bulbo seco e bulbo úmido, um termômetro de globo negro e um Termohigrografo. As leituras das variáveis ambientais foram realizadas às 9:00 e às 15:00 horas, obedecendo às normas meteorológicas internacionais e para calcular o Índice de Temperatura do Globo Negro e Umidade (ITGU) e o Índice de Temperatura e Umidade (THI) utilizou-se as seguintes fórmulas: ITGU $=\mathrm{TGn}+0,36$ Tpo $+41,5$ e THI $=0,72($ Tbs + Tbu $)+40,6$ conforme Buffington et al. (1981) e Kelly \& Bond (1971), respectivamente. 
TABELA 1 - Composição bromatológica das dietas experimentais com base na matéria seca em função dos diferentes níveis de Lipídeo (L) e Proteína (PB), de acordo com recomendações do AFRC (1995).

\begin{tabular}{|c|c|c|c|c|c|c|c|c|c|}
\hline & \multicolumn{9}{|c|}{ Lipídeo } \\
\hline & \multicolumn{3}{|c|}{$2 \%$} & \multicolumn{3}{|c|}{$4 \%$} & \multicolumn{3}{|c|}{$6 \%$} \\
\hline & \multicolumn{3}{|c|}{ Proteína bruta } & \multicolumn{3}{|c|}{ Proteína bruta } & \multicolumn{3}{|c|}{ Proteína bruta } \\
\hline & $12 \%$ & $15 \%$ & $18 \%$ & $12 \%$ & $15 \%$ & $18 \%$ & $12 \%$ & $15 \%$ & $18 \%$ \\
\hline \multicolumn{10}{|l|}{ Ingredientes } \\
\hline Farelo de Milho & 26,97 & 19,70 & 11,61 & 39,73 & 31,09 & 24,33 & 46,76 & 38,59 & 30,60 \\
\hline Farelo de trigo & 9,44 & 7,67 & 8,44 & 2,39 & 6,12 & 1,78 & 0 & 0 & 0 \\
\hline Feno de Tifton & 59,67 & 60,20 & 59,57 & 48,64 & 45,89 & 48,10 & 39,99 & 40 & 39,99 \\
\hline Oleo de girassol & 2 & 2 & 2 & 4 & 4 & 4 & 6 & 6 & 6 \\
\hline Calcáreo & 0,07 & 0 & 0,09 & 0 & 0,200 & 0 & 0,059 & 0,05 & 0,008 \\
\hline Fosfato bicálcico & 0,27 & 0,25 & 0,02 & 0,59 & 0,21 & 0,37 & 0,67 & 0,54 & 0,41 \\
\hline Farelo de soja & 1,07 & 9,68 & 17,87 & 4,14 & 11,99 & 20,93 & 6,03 & 14,33 & 22,59 \\
\hline Mistura mineral & 0,5 & 0,5 & 0,5 & 0,5 & 0,5 & 0,5 & 0,5 & 0,5 & 0,4 \\
\hline \multicolumn{10}{|l|}{ Composição } \\
\hline Matéria seca & 90,06 & 90,06 & 90,03 & 90,05 & 90 & 90,01 & 90,08 & 90,07 & 90,14 \\
\hline $\begin{array}{l}\text { Energia metabolizável } \\
\text { (Mcal/kg MS) }\end{array}$ & 9,54 & 9,55 & 9,55 & 10,79 & 10,8 & 10,8 & 11,7 & 11,68 & 11,68 \\
\hline Proteína metabolizável & 5,18 & 7,29 & 9,42 & 5,81 & 8 & 10,07 & 6,27 & 8,38 & 10,49 \\
\hline Extrato etéreo & 5,85 & 5,67 & 5,43 & 7,86 & 7,57 & 7,44 & 9,79 & 9,57 & 9,36 \\
\hline Proteína bruta & 12 & 15 & 18 & 12 & 15 & 18 & 12 & 15 & 18 \\
\hline Cálcio & 0,41 & 0,41 & 0,38 & 0,41 & 0,41 & 0,41 & 0,41 & 0,41 & 0,41 \\
\hline Fósforo & 0,33 & 0,33 & 0,32 & 0,33 & 0,33 & 0,33 & 0,33 & 0,33 & 0,33 \\
\hline
\end{tabular}

Os parâmetros fisiológicos estudados foram: temperatura retal (TR), freqüência respiratória (FR) e temperatura superficial (TS) dos animais. A TR foi mensurada com auxílio de termômetro clínico veterinário introduzido diretamente no reto do animal por dois minutos. A FR foi determinada por meio da auscultação indireta das bulhas, com auxílio de estetoscópio flexível, ao nível da região laringo-traqueal e expressa em mov/min, conforme metodologia descrita por Dirksen et al. (1990). A temperatura superficial (TS) foi obtida por meio das médias das temperaturas da pele em oito pontos da pele do animal: fronte, pescoço, costado, lombo, coxa, ventre, canela e testículos, utilizando-se de um termômetro infravermelho
(ST3 - RAYTEK). Os dados foram coletados às 9:00 e às 15:00 horas.

Para o estudo dos parâmetros hematológicos foi realizada colheita de sangue dos animais, através de venipunção da jugular, colhendo-se cinco $\mathrm{mL}$ de sangue em tubo a vácuo (Vacuette, Creiner Bione, Vacuette do Brasil LTDA, Campinas - São Paulo) com anticoagulante etilenodiaminotetracético, sal dissódico (EDTA) a 10\% para realização do eritrograma. As variáveis hematológicas estudadas foram: hematócrito (HT), eritrócitos (ER), hemoglobina (HB), volume globular médio (VGM) e hemoglobina corpuscular média (CHCM). A contagem global de eritrócitos foi realizada em câmara de Newbauer, 
usando-se a solução de Gower como diluidor. Para a determinação do hematócrito utilizou-se o método do microhematócrito por 15 minutos, o teor de HB foi obtido pelo método de cianometahemoglobina, com leitura por espectofotometria (Espectofotômetro Baush-Lomb Spectronic 20) a $525 \mathrm{~nm}$. O VGM foi calculado pela fórmula de Wintrobe (BIRGEL, 1982) e o CHCM, foi calculado segundo Ferreira Neto \& Viana (1977). Os dados obtidos foram submetidos à análise de variância utilizando-se o programa SAS Institute (1996).

\section{RESULTADOS E DISCUSSÃO}

As variáveis ambientais observadas durante o experimento e os valores médios do ITGU e do THI encontram-se na Tabela 2.

A análise de variância revelou efeito de turno $(\mathrm{P}<0,05)$ para todas as variáveis ambientais, sendo os maiores valores encontrados no turno da tarde. As médias das temperaturas máxima (Tmáx) e mínima (Tmin), foram de $37,21^{\circ} \mathrm{C}$ e $25,25{ }^{\circ} \mathrm{C}$, respectivamente. As temperaturas de bulbo seco, a sombra, nos dois turnos, foram de $30,72{ }^{\circ} \mathrm{C}$ e $36,77^{\circ} \mathrm{C}$, respectivamente, as quais se apresentaram acima da temperatura máxima de conforto térmico para caprinos de acordo com a classificação de Baêta \& Souza (1997), que estabelece valores de $20^{\circ} \mathrm{C}$ a $30^{\circ} \mathrm{C}$.

Apesar de estar na ausência de radiação solar direta os valores médios do ITGU apresentaram-se elevados, nos turnos da manhã e tarde (80,16 e 87,17, respectivamente) contudo, não podem ser considerados como situação perigosa para caprinos mestiços de Anglo-Nubiano com SRD, uma vez que os mesmos não apresentaram respostas fisiológicas fora dos padrões normais para a espécie.

Os valores médios do THI nos dois turnos apesar de diferirem estatisticamente $(\mathrm{P}<0,05)$ apresentaram-se próximos aos valores do ITGU, devido à pouca variação da TGN com relação a TBS, em virtude da condição de sombra do local onde foi desenvolvido o experimento.

As médias da temperatura retal (TR) e frequiência respiratória (FR) em função dos diferentes níveis de proteína e lipídeo na dieta, encontram-se na Tabela 3.

A análise de variância não revelou interação significativa $(\mathrm{P}>0,05)$ entre os diferentes níveis de lipídeo e proteína nas dietas e os parâmetros fisiológicos, temperatura retal (TR) e frequiência respiratória (FR). Com relação ao fator turno houve efeito significativo $(\mathrm{P}<0,05)$ para TR $\left(38,75\right.$ e $\left.39,02{ }^{\circ} \mathrm{C}\right)$ e FR (41 e $\left.67 \mathrm{mov} / \mathrm{min}\right)$ nos períodos da manhã e tarde, respectivamente, tendo o turno da tarde apresentado as maiores médias.

A ausência de diferença significativa para TR e FR em função dos diferentes níveis de proteína e lipídeo na dieta, provavelmente, ocorreu devido ao estresse não ter sido muito elevado já que, os animais não sofreram influência da radiação solar direta. Entretanto, houve diferença significativa entre os turnos, em função das temperaturas serem mais elevadas no período da tarde, resultados esses que concordam com Medeiros et al. (1998) e Silva et al. (2003), que também verificam elevação dos parâmetros no turno da tarde e com Ingram \& Mount (1975) ao relatarem, que como aumento da temperatura ambiente, a eficiência das perdas de calor por condução, convecção e radiação diminuem, devido ao menor gradiente de temperatura entre a pele do animal e os arredores, nessa situação, o animal pode até certo ponto manter a temperatura corporal por meio de vasodilatação, aumentando o fluxo sanguíneo periférico e a temperatura superficial, no entanto, se a temperatura ambiente continuar a subir o animal passa a depender da perda de calor por evaporação através da respiração para manter a homeotermia.

TABELA 2 - Médias registradas para a temperatura de bulbo seco (TBS), temperatura de bulbo úmido (TBU), temperatura de globo negro (TGN), do índice de temperatura do globo negro (ITGU) e índice de temperatura e umidade (THI) no período de novembro a dezembro de 2003.

\begin{tabular}{|c|c|c|c|c|c|}
\hline \multirow[b]{2}{*}{ Turnos } & \multicolumn{3}{|c|}{ Temperaturas $\left({ }^{\circ} \mathrm{C}\right)$} & \multirow[b]{2}{*}{ ITGU } & \multirow[b]{2}{*}{ THI } \\
\hline & TBS & TBU & TGN & & \\
\hline Manhã & $30,72^{\mathrm{A}}$ & $22,41^{\mathrm{A}}$ & $31,79^{\mathrm{A}}$ & $80,16^{\mathrm{A}}$ & $78,90^{\mathrm{A}}$ \\
\hline Tarde & $36,77^{\mathrm{B}}$ & $23,12^{\mathrm{B}}$ & $39,94^{\mathrm{B}}$ & $87,17^{\mathrm{B}}$ & $83,72^{\mathrm{B}}$ \\
\hline $\mathrm{CV}(\%)$ & 1,7 & 2,2 & 2,8 & 1,3 & 0,7 \\
\hline
\end{tabular}

Médias seguidas de letras diferentes na coluna diferem estatisticamente entre si $(\mathrm{P}<0,05)$ pelo teste de Tukey. 
Para a temperatura superficial (TS), houve interação significativa $(\mathrm{P}<0,05)$, para a dieta com $15 \%$ de proteína e $2 \%$ de lipídeo e para o turno, conforme demonstrado na Tabela 4.

Embora a temperatura superficial média do grupo alimentado com $15 \%$ de proteína bruta e $2 \%$ de lipídeo tenha se apresentado ligeiramente inferior aos demais grupos, não podemos indicá-la como sendo a melhor dieta, uma vez que não foram observadas diferenças significativas $(\mathrm{P}>0,05)$ para a TR e FR, parâmetros que melhor indicam uma situação de estresse.

As médias dos parâmetros hematológicos; hematócrito (HT), eritrócitos (ER), hemoglobina (HB), volume globular médio (VGM) e hemoglobina corpuscular média (CHCM), observados no período experimental, encontram-se na Tabela 5.

A análise de variância não revelou interação significativa $(\mathrm{P}>0,05)$ entre os diferentes níveis de lipídeo e proteína nas dietas e os parâmetros hematológicos.

Não houve efeito significativo $(\mathrm{P}>0,05)$ das dietas sobre os parâmetros hematológicos, HT, ER, HB, VGM e CHGM, os quais apresentaram-se dentro dos valores normais de referência para caprinos, estabelecidos por Ferreira Neto \& Viana (1977) e Jain (1993).

TABELA 3 - Temperatura retal (TR) e frequência respiratória (FR) de caprinos mestiços de Anglo-Nubiano com sem raça definida (SRD) alimentados com diferentes níveis de proteína e lipídeo na dieta.

\begin{tabular}{|c|c|c|c|}
\hline \multirow{2}{*}{ Fatores } & \multirow{2}{*}{$(\%)$} & \multicolumn{2}{|c|}{ Parâmetros Fisiológicos } \\
\hline & & $\operatorname{TR}\left({ }^{\circ} \mathrm{C}\right)$ & FR (Mov/min) \\
\hline \multirow[t]{3}{*}{ Proteína } & 12 & 38,86 & 58 \\
\hline & 15 & 38,94 & 52 \\
\hline & 18 & 38,86 & 50 \\
\hline \multirow[t]{3}{*}{ Lipídeo } & 2 & 38,90 & 58 \\
\hline & 4 & 38,88 & 52 \\
\hline & 6 & 38,87 & 51 \\
\hline \multirow[t]{2}{*}{ Turnos } & Manhã & $38,75^{\mathrm{A}}$ & $41^{\mathrm{A}}$ \\
\hline & Tarde & $39,02^{\mathrm{B}}$ & $67^{\mathrm{B}}$ \\
\hline CV (\%) & & 0,4 & 21,3 \\
\hline
\end{tabular}

Médias seguidas de letras diferentes na coluna diferem estatisticamente entre si $(\mathrm{P}<0,05)$ dentro de cada parâmetro.

TABELA 4 - Temperatura superficial (TS) de caprinos mestiços de Anglo-Nubiano com SRD em função de diferentes níveis de proteína bruta e lipídeo na dieta.

\begin{tabular}{cccc}
\hline Lipídeo & \multicolumn{3}{c}{ Proteína bruta } \\
\cline { 2 - 4 }$(\boldsymbol{\%})$ & $\mathbf{1 2}(\boldsymbol{\%})$ & $\mathbf{1 5}(\boldsymbol{\%})$ & $\mathbf{1 8}(\boldsymbol{\%})$ \\
\hline 2 & $31,53^{\mathrm{B}}$ & $30,86^{\mathrm{A}}$ & $31,45^{\mathrm{B}}$ \\
4 & $31,55^{\mathrm{B}}$ & $31,65^{\mathrm{B}}$ & $31,70^{\mathrm{B}}$ \\
6 & $31,66^{\mathrm{B}}$ & $31,83^{\mathrm{B}}$ & $31,65^{\mathrm{B}}$ \\
\hline Manhã & $30,04^{\mathrm{B}}$ & $29,89^{\mathrm{B}}$ & $30,08^{\mathrm{B}}$ \\
Tarde & $33,12^{\mathrm{B}}$ & $33,47^{\mathrm{A}}$ & $33,09^{\mathrm{B}}$ \\
\hline
\end{tabular}

Médias seguidas de letras diferentes na coluna diferem estatisticamente entre si $(\mathrm{P}<0,05)$ pelo teste de Tukey.

Ciênc. agrotec., Lavras, v. 30, n. 1, p. 154-161, jan./fev., 2006 
TABELA 5 - Parâmetros hematológicos, hematócrito (HT), eritrócitos (ER), hemoglobina (HB), volume globular médio (VGM) e hemoglobina corpuscular média (CHCM) de caprinos mestiços de Anglo-Nubiano com SRD, alimentados com dietas contendo diferentes níveis de proteína e lipídeo.

\begin{tabular}{cccccc}
\hline Proteína $(\%)$ & HT $(\%)$ & ER $\left(\mathbf{x} 10^{\mathbf{6}} / \mathbf{m m}^{\mathbf{3}}\right)$ & HB $(\mathbf{g} / \mathbf{d l})$ & VGM $\left(\mu^{3}\right)$ & CHCM \\
\hline 12 & $28,11^{\mathrm{A}}$ & $14,10^{\mathrm{A}}$ & $9,34^{\mathrm{A}}$ & $19,84^{\mathrm{A}}$ & $33,24^{\mathrm{A}}$ \\
15 & $26,22^{\mathrm{A}}$ & $14,04^{\mathrm{A}}$ & $8,71^{\mathrm{A}}$ & $18,65^{\mathrm{A}}$ & $33,22^{\mathrm{A}}$ \\
18 & $28,77^{\mathrm{A}}$ & $14,96^{\mathrm{A}}$ & $9,57^{\mathrm{A}}$ & $19,19^{\mathrm{A}}$ & $33,28^{\mathrm{A}}$ \\
Lipídeo (\%) & & & & \\
2 & $26,77^{\mathrm{A}}$ & $14,03^{\mathrm{A}}$ & $8,90^{\mathrm{A}}$ & $19,10^{\mathrm{A}}$ & $33,23^{\mathrm{A}}$ \\
4 & $28,33^{\mathrm{A}}$ & $14,38^{\mathrm{A}}$ & $9,42^{\mathrm{A}}$ & $19,68^{\mathrm{A}}$ & $33,25^{\mathrm{A}}$ \\
6 & $28,00^{\mathrm{A}}$ & $14,70^{\mathrm{A}}$ & $9,31^{\mathrm{A}}$ & $18,91^{\mathrm{A}}$ & $33,25^{\mathrm{A}}$ \\
\hline CV $(\%)$ & 10,8 & 8,8 & 10,7 & 4,6 & 0,3 \\
\hline
\end{tabular}

Médias seguidas de letras maiúsculas iguais na coluna não diferem estatisticamente entre si ( $\mathrm{P}>0,05)$.

De acordo com Paes et al. (2000), os parâmetros sangüíneos têm sido utilizados mundialmente para avaliar o estado de saúde dos animais e também como indicadores de estresse calórico. Podendo, vários fatores como espécie, sexo, idade, estado fisiológico, hora do dia, umidade relativa do ar, temperatura ambiente e atividade muscular, provocar alteração desses parâmetros (BIRGEL JÚNIOR et al., 2001; JAIN, 1993). Com a redução da ingestão de alimentos em virtude do incremento calórico produzido pela digestão da fibra, os animais entram em balanço energético negativo, fazendo uso de suas reservas corporais e desencadeando alteração nos seus parâmetros hematológicos. Lee et al. (1974) ao estudarem o efeito de estresse em bovinos, observaram que os animais apresentaram uma redução do número de eritrócitos, hemoglobina e do volume globular em virtude da hemoconcentração decorrente da redução da ingestão de alimentos e água.

A ausência de diferença significativa para o HT pode ser explicada pela ausência de um estresse severo, já que os animais estavam confinados e protegidos da radiação solar. Para Gütler et al. (1986), a proporção de volume das células sangüíneas depende da solicitação física dos animais, sendo que os animais sob esforço físico apresentam maiores valores para o HT em função da perda de líquido através da sudação e respiração. Segundo Lee et al. (1974), o hematócrito é uma estimativa da massa de eritrócitos em relação ao volume sangüíneo, podendo aumentar em função de uma desidratação, devido à perda de líquidos, mecanismos evaporativos de dissipação de calor ou diminuir em função de anemias, prenhes avançadas, hemólise e severidade da carga calórica imposta sobre o animal.

Os ER apresentaram-se superiores à média descrita por Jain (1993), provavelmente devido à alimentação balanceada e de boa qualidade que os animais receberam. Segundo Gütler et al. (1986), os caprinos possuem o maior número de eritrócitos entre os animais domésticos, uma vez que seus glóbulos vermelhos são muito pequenos. Podendo uma redução nessas células estar relacionada com alimentação deficiente, o que também reduz o valor do hematócrito. Como a hemoglobina representa aproximadamente $92 \%$ dos componentes orgânicos dos eritrócitos, ocorre também redução da hemoglobina.

Com relação aos valores encontrados para HB, estes apresentaram-se superiores $(8,71 \mathrm{a} 9,57 \mathrm{~g} / \mathrm{dl})$ aos relatados por Igbokwe et al. (1998), mas dentro da faixa encontrada por Unanian (1986) e próximo ao valor mínimo (7,0 g/dl) descrito por Gutler et al. (1986). Sabendo-se que a função da HB consiste no transporte de oxigênio dos pulmões para os diferentes tecidos e em uma situação de estresse, o valor da HB deve se apresentar elevado, em função da elevação da taxa de consumo de oxigênio, os valores da HB baixos confirmam a ausência de um estresse severo.

Para o VGM e CHCM não foi encontrado diferença significativa $(\mathrm{P}>0,05)$ entre os grupos e os valores apresentaram-se dentro dos valores normais de referência para a espécie de acordo com Ferreira Neto \& Viana (1977). 


\section{CONCLUSÃO}

Os diferentes níveis de proteína e lipídeo na dieta não exerceram efeito sobre os parâmetros fisiológicos e hematológicos de caprinos mestiços de Anglo-Nubiano com SRD.

\section{REFERÊNCIAS BIBLIOGRÁFICAS}

AGRICULTURAL AND FOOD RESEARCH COUNCIL. Energy and protein reuirements of ruminants: in advisory manual prepared by the AFRC. Wallingford: C.A.B. International, 1995. $159 \mathrm{p}$.

APLLEMAN, R. D.; DELOUCHE, J. C. Behavioral, physiological and biochemical responses of goats to temperature, $0^{\circ}$ to $40^{\circ} \mathrm{C}$. Journal Animal Science, Champaign, v. 17, p. 326-335, 1958.

BAÊTA, F. C.; SOUZA, C. F. Ambiência em edificações rurais conforto térmico. Viçosa: UFV, 1997. $246 \mathrm{p}$.

BIRGEL, E. H. Hematologia clínica veterinária. In: BIRGEL, E. H.; BENESI, F. J. Patologia clínica veterinária. São Paulo: Sociedade Paulista de Medicina Veterinária, 1982. p. 2-34.

BIRGELJÚNIOR, E. H.; D'ANGELINO, J.L.; BENESI,F. J.; BIRGEL, E. H. Valores de referência do eritrograma de bovinos da raça Jersey criados no estado de São Paulo. Arquivo Brasileiro de Medicina Veterinária e Zootecnia, Belo Horizonte, v. 53, n. 2, 2001.

BRIDGES, T. C.; TURNER, L. W.; STAHLY, T. S.; USRY, J. L.; LOEWER, O. J. Modeling the physiological growth of swine. Part I: model logic and growth concepts. Transactions of the ASAE, [S.1.], v. 35, n. 3, p. 1019-1028, 1992.

BUFFINGTON, D. E.; COLLAZO-AROCHO, A.; CANTON, G. H.; PITT, D. Black globe-humidity index (BGHI) as comfort equation for dairy cows. Transactions of the Asae, [S.l.], p. 711-713, 1981.

BUNTING, L. D.; STICKER, L. S.; WOZNIAK, P. J. Effect of ruminal escape protein and fat on nitrogen utilization in lambs exposed to elevated ambient temperatures. Journal Animal Science, Champaign, v. 70, p. 1518-1525, 1992.

DIRKSEN, G.; GRUNDER, H. D.; STOBER, M. Rosenberger exame clínico dos bovinos. 3. ed. Rio de Janeiro: Guanabara Koogan, 1990. 419 p.
FERREIRA NETO, J. M.; VIANA, E. S. Patologia clínica veterinária. Belo Horizonte: Rabelo, 1977. 279 p.

GIGER-REVERDIN, S.; MORAND-FEHR, P.; TRAN, G. Literature survey of the influence of dietary fat composition on methane production in dairy cattle. Livestock Production Science, Amsterdam, v. 82, p. 73-79, 2003.

GÜTLER, H.; KETZ, A.; KOLB, E. Fisiologia veterinária. 2. ed. São Paulo: Guanabara, 1986. 569 p.

IGBOKWE, I. O.; RIBADU, A. Y.; BUKAR, M. M. Erytrocyte gluthione concentration in Nigwrian Sahel goats. Small Ruminant Research, [S.I.], v. 30, p. 1-6, 1998.

INGRAM, D. L.; MOUNT, L. E. Man and animals in hot environments. New York: Springer-Verlag, 1975. 185 p.

JAIN, N. C. Essentials of veterinary hematology. Philadelphia: Lea \& Febiger, 1993. 417 p.

KELLY, C. F.; BOND, T. E. Bioclimatic factors and their measurement. In: . A guide to environmental research on animals. Washington: [s.n.], 1971. p. 7-92.

LEE, J. A.; ROUSSEL, J. D.; BEATTY, J. F. Effect of temperature season on bovine adrenal cortical function, blood cell profile, and milk production. Journal of Dairy Science, Champaign, v. 59, n. 1, p. 104-108, 1974.

LU, C. D. Effects of heat stress on Goat Production. Small Ruminant Research, [S.1.], v. 2, p. 151-162, 1989.

MEDEIROS, L. F.; SCHERER, P. O.; VIEIRA, D. H.; SOUSA, J. C. D. Frequência respiratória e cardíaca em caprinos de diferentes raças e idades. In: REUNIÃO ANUAL DA SOCIEDADE BRASILEIRA DE ZOOTECNIA, 35., 1998, Botucatu. Anais... Botucatu: Sociedade Brasileira de Zootecnia, 1998. CD-ROM.

MULLER, C. J. C.; BOTHA, J. A.; SMITH, W. A. Effect of shade on various parameters of Friesian cows in a Mediterranean climate in South Africa: 3. behavior. South African Journal of Animal Science, Pretoria, v. 24, p. 61-66, 1994.

PAES, P. R.; BARIONI, G.; FONTEQUE, J. R. Comparação dos valores hematológicos entre caprinos fêmeas da raça Parda Alpina de diferentes faixas etárias. Veterinária Notícias, [S.1.], v. 6, n. 1, p. 43-49, 2000. 
SALLA, L. E.; FISCHER, V.; FERREIRA, E. X.; MORENO, C. B.; STUMPF JUNIOR, W.; DUARTE, L. D. Comportamento ingestivo de vacas Jersey alimentadas com dietas contendo diferentes fonts de gorduranos primeiros 100 dias de lactação. Revista Brasileira de Zootecnia, Viçosa, v. 32, n. 3, p. 683-689, 2003.

SAS INSTITUTE. SAS user's guide: statistics. 6. ed. Cary, $1996.596 \mathrm{p}$.

SILANIKOVE, N. Effects of heat stress on the welfare of extensively managed domestic ruminants. Livestock Production Science, Amsterdam, v. 67, p. 1-18, 2000.

SILVA, G. A.; SOUZA, B. B.; SILVA, E. M. N.; SILVA, A. K. B.; COSTA, A. A. A.; AZEVEDO, S. A.; AZEVEDO
NETO, J. Determinação de parâmetros fisiológicos e gradientes térmicos de caprinos no semi-árido paraibano. In: SIMPÓSIO INTERNACIONAL SOBRE CAPRINOS E OVINOS DE CORTE, 2., 2003, João Pessoa. Anais... João Pessoa: Governo do Estado da Paraíba, 2003. CDROM.

UNANIAN, M. M. Blood parameters of young goats in semi-arid region of the northeast of Brazil. Pesquisa Agropecuária Brasileira, Brasília, v. 21, n. 3, p. 293-301, 1986.

WEST, J. W. Nutritional strategies for managing the heatstressed dairy cow. Journal Animal Science, Champaign, v. 77, n. 2, p. 21-35, 1999. Supplement. 